\title{
Crisis and Emergency Risk Communication as an Integrative Model
}

\author{
BARBARA REYNOLDS \\ Office of Communication, Centers for Disease Control and Prevention, \\ Atlanta, Georgia
}

\section{MATTHEW W. SEEGER}

Department of Communication, Wayne State University, Detroit, Michigan, USA

\begin{abstract}
This article describes a model of communication known as crisis and emergency risk communication (CERC). The model is outlined as a merger of many traditional notions of health and risk communication with work in crisis and disaster communication. The specific kinds of communication activities that should be called for at various stages of disaster or crisis development are outlined. Although crises are by definition uncertain, equivocal, and often chaotic situations, the CERC model is presented as a tool health communicators can use to help manage these complex events.
\end{abstract}

The anthrax attack of September 2001 was arguably one of the most public and disruptive public health emergencies of recent history. Although much larger and widespread health risks exist, such as the avian flu, the emergence of sudden acute respiratory syndrome (SARS), the upswing in skin cancer, and the recent West Nile virus outbreaks, anthrax was new in terms of the perceived threat and the intentional nature of the attack. Moreover, because anthrax was connected in terms of time and perception to the 9/11 World Trade Center disasters, it created heightened public concern and widespread public outrage. The event placed significant pressure on the public health community to communicate effectively within a context of immediacy, threat, and high uncertainty.

Health professionals, including those in the health communication domain, often frame their messages regarding the possibility of serious public health harm as risk communication (Covello, 1992; Freimuth, Linnan, \& Potter, 2000; Heath, 1994; Sandman, 2002; Witte, Meyer, \& Martel, 2000). In organizational settings, including corporate contexts and disaster management, however, these perspectives more often have been framed as crisis communication (Barton, 2001; Coombs, 1995; Seeger, Sellnow, \& Ulmer, 1998, 2001). In addition, the public health community has engaged in issue management regarding health promotion and has sought to

An earlier version of this article was presented at the National Communication Association Convention, November 2002.

Address correspondence to Matthew W. Seeger, Department of Communication, Wayne State University, 585 Manooqian Hall, Detroit, MI 48201, USA. E-mail: Matthew.Seeger @)Wayne.edu 
influence public policy regarding health issues. The anthrax episode, however, required new forms of public health communication. In this discussion, we identify the distinguishing features of these forms of public health communication. We propose a comprehensive approach to emergency public health events that incorporates both risk communication and crisis communication into a hybrid form known as CERC.

\section{Communication During Crises and Disasters}

In general, the management of natural disasters and public health emergencies has always included a significant communication component in the form of warnings, risk messages, evacuation notifications, messages regarding self-efficacy, information regarding symptoms and medical treatment, among many others. Different kinds of crises, however, manifest different forms of threat and different communication exigencies (Pauchant \& Mitroff, 1992; Seeger, Sellnow \& Ulmer, 2003). Some kinds of natural disasters, such as hurricanes, for example, may prompt recommendations that residents stockpile water and food or that that they evacuate. Hazardous chemical spills often result in recommendations that residents close windows, shut off all outside ventilation, and shelter in place. Tornado warnings usually include recommendations that residents seek shelter immediately. Floods usually are accompanied by recommendations that residents drink bottled water or boil water to avoid waterborne pathogens (Sellnow, Seeger, \& Ulmer, 2002).

Public health emergencies, in contrast, generally concern the outbreak of particular diseases or the identification of specific risks from environmental or life-style factors. Foodborne pathogens, such as ground beef contaminated with e.coli 157:H7, for example, create a risk to the general public health. In such cases, public health agencies will track the sources of the disease, undertake actions to stop the contamination, issue warnings and recalls, and provide the public with information about symptoms, treatments, and ways to avoid exposure (Fischhoff \& Downs, 2001; Ulmer \& Sellnow, 2000). During the outbreak of West Nile virus, public health agencies have disseminated information about the nature and frequency of the disease and the level of risk and have offered guidelines for how to avoid mosquito bites. Typically, these activities rely on the mass media and general public education campaigns to spread the word.

The specter of bioterrorism raised by the 9/11 attacks and the anthrax outbreak, however, raised the possibility of intentional widespread harm to the public health. Some scenarios involving agents such as botulism, plague, anthrax, smallpox, VX, mustard and sarin gas, as well as radiological materials could cause widespread harm to the public health Centers for Disease Control and Prevention ([CDC], 2002; National Council on Radiation Protection \& Measurement, 2001). Moreover, emerging diseases such as SARS or avian flu HN51, although less malevolent in their origins, create similarly frightening scenarios of widespread harm to the public health. The technical assessment of hazard, then, suggests a high level of risk.

These risks are also new to the general public and, therefore, include low familiarity, are seen as unnatural and exotic, and create high levels of uncertainty. In most cases, they involve organisms that cannot be seen and diseases and symptoms that have not before been evident in the general population. This general lack of familiarity is likely to enhance the perceived risk by the general public (Sandman, 2002). In the case of an intentional bioterrorism attack, the perceived outage surrounding the 
event also will be high, further enhancing the perceived risk. Bioterrorism is also likely to create very high levels of uncertainty. Moreover, these emergent threats require more cooperation between various governmental agencies, such as various law enforcement groups; elected officials at local, state, and national levels; and the emergency management and Homeland Security infrastructure. In some cases, threats may become politicized, adding complexity. As with other forms of risk communication, these emergent threats create challenges for the medical and public health community to communicate in accurate, credible, timely, and reassuring ways.

\section{Risk and Crisis Communication}

Risk communication is a mature area of research and practice that informs many public health campaigns. Heath (1994) suggests, "Risk communication deals with risk elements, whether they are appropriately tolerable, and risk consequences" (p. 257). Covello (1992) defines risk communication as "the exchange of information among interested parties about the nature, magnitude, significance, or control of a risk" (p. 359). The National Research Council (1989) describes risk communication as "an interactive process of exchange of information and opinion among individuals, groups, and institutions" (p. 2). Risk communication, then, is closely associated with threat sensing and assessment. In practice, risk communication most often involves the production of public messages regarding health risks and environmental hazards. Witte and colleagues (2000) observe that risk communication is most closely grounded in research on fear appeals as a persuasive device. These messages seek to induce behavioral change by presenting a threat and describing a behavior or behavioral change that may alleviate the threat. Efficacy is the effectiveness or feasibility of the behavioral change in alleviating the threat while self-efficacy refers to the belief that the recommendation can be carried out (Egbert \& Parrott, 2001; Witte et al., 2000, p. 20). Risk communication is also grounded in an assumption that the public has a generalized right to know about hazards and risks. The availability of information allows the public to make informed choices regarding risk. In this way risk communication facilitates decision making and risk sharing.

Sandman's $(1993,2002)$ model of risk as a function of hazard (defined as technical assessment of risk) and outrage (defined as a cultural view of risk) has framed many of the efforts to communicate about various public health risks. Moreover, his detailing of the factors associated with outrage has provided a helpful framework for assessing the public's response to various risk factors. Other basic principles of effective communication also have informed the practice of risk communication. Audiences tend to simplify messages. Credibility is important to the believability and effectiveness of messages. Risk messages should include some self-efficacy action that can be taken to reduce the risk (Egbert \& Parrott, 2001). Messages are more effective when they are strategically matched to audience needs, values, background, culture, and experience (Murray-Johnson, Witte, Liu, \& Hubbel, 2001). Risk messages should be clear and simple, appeal to reason and emotion, and offer solutions to problems (Friemuth et al., 2000). Much of risk communication as practiced in public health incorporates these features in public messages, usually carried in the mainstream media, as general persuasive campaigns. They seek to inform the public and change behavior in ways that protect and improve the public health and safety. 
Communication, usually in the form of public relations (PR), is also a traditional activity following a crisis. (see Coombs, 1995; Seeger et al., 1998.) Organizational crises, such as a plant explosion, employee violence, toxic spill, or transportation accident usually generate widespread public and media interest and often criticism. This crisis communication role of PR derives from the need for skilled communicators to strategically defend and explain the organization's position in the face of crisis-induced criticism, threat, and uncertainty. During crises, PR practitioners typically face a hostile and inquisitive press and provide accounts of what went wrong, why, and what is being done in response. Thus, historically, crisis communication served as spokesperson, buffer, and disseminator of information (Seeger et al., 1998). This perspective most often involved two defensive strategies: "deny that a crisis exists, refuse to answer media questions, and resist involvement by appropriate government agencies" or "releasing partial, often inaccurate and delayed information while concealing unfavorable facts" (Wilcox, Ault, \& Agee, 1986, p. 310). This form of post-crisis PRs contributed to a cynical view of organizations and PR. In general, it served to reduce organizational credibility and often significantly enhanced the harm (see Guth, 1995; Small, 1991; Seeger \& Bolz, 1996). As the role of PRs has expanded and as crises have become more common, so too has the notion of crisis communication. One fundamental change involves a cardinal tenet among PRs practitioners that an honest, candid, prompt, accurate, and complete response to a crisis is always called for (Small, 1991).

Crisis communication, then, involves the sending and receiving of messages "to prevent or lessen the negative outcomes of a crisis and thereby protect the organization, stakeholders, and/or industry from damage" (Coombs, 1999, p. 4). As such, it is part of the larger crisis management function (Seeger et al., 1998). Fearn-Banks (2002) suggests that "Crisis communication is verbal, visual, and/or written interaction between the organization and its stakeholders (often through the media) prior to, during and after a negative occurrence" (p. 480). These communication processes are designed to reduce and contain harm, provide specific information to stakeholders, initiate and enhance recovery, manage image and perceptions of blame and responsibility, repair legitimacy, generate support and assistance, explain and justify actions, apologize, and promote healing, learning, and change (Seeger et al., 2003). Crisis communication seeks to explain the specific event, identify likely consequences and outcomes, and provide specific harm-reducing information to affected communities in an honest, candid, prompt, accurate, and complete manner.

One of the principal distinctions between crisis communication and risk communication concerns their origins. Crisis communication typically is associated with PRs and is grounded in efforts to strategically manage and frame public perceptions of an event so that harm is reduced for both the organization and stakeholders. Public Relations has sought to "develop communication models and frameworks that inform practice and which help limit and alleviate the damage to both the organization and other crisis stakeholders such as the community, victims, and their families" (Seeger et al., 1998, p. 66). Crisis communication also has begun to draw more heavily on the need to communicate during public emergencies, earthquakes, floods, hurricanes, and so on (Auf Der Heide, 1989; Sellnow, Seeger, \& Ulmer, 2002). This may involve disseminating information about evacuations, about harm mitigation resources and procedures, and about possibilities of additional harm (see Mileti \& Sorensen, 1990; Sorensen, 2000). Emergency public information, most often associated with natural disasters, is designed to "protect health, safety, and the environment 
by keeping the public informed" and "to restore public confidence in the organization's ability to manage an incident" (Mileti \& Sorensen, 1990, p. 4).

Risk communication, in contrast, most often is associated with the identification of risks to the public health and efforts to persuade the public to adopt more healthy, less risky behaviors (Freimuth et al., 2000). Thus, public campaigns regarding the hazards of cigarette smoking are the archetype for risk communication. Similar campaigns regarding HIV/AIDS and safe sex, drunk driving, binge drinking, vaccines, drug abuse, infectious diseases, exercise, and various kinds of disease and health screenings have sought to disseminate information about risk and persuade the public to modify their behaviors accordingly (see Murray-Johnson et al., 2001; Rogers \& Deckner, 1975; Smart \& Fejer, 1974; Witte, 1992). Risk communication also involves the dissemination of information about environmental hazards such as those associated with chemical and toxic contaminates, carcinogens, pathogens, and related environmental hazards (Powell \& Leiss, 1997). Lundgren (1994) also describes communication about chronic, endemic diseases with long induction times as care communication. This form of ongoing communication encourages long-term behavioral and environmental changes. The underlying assumptions of these various perspectives is that informing the public may allow them to make choices to avoid or reduce exposures, manage a condition or a risk, or both. Thus, federal and state environmental protection agencies provide fish consumption advisories detailing the level of contamination in various species. In addition, more specific and detailed warnings may be found in a variety of pamphlets and brochures disseminated by heath providers, social service agencies, and in schools. Finally, risk communication also is associated with natural disasters, principally in the form of preevent warnings, such as evacuation advisories, and in postevent recommendations about avoiding additional harm, such as boiling drinking water in the case of a flood.

One focus of risk communication might be loosely described as seeking to create a rational understanding of risk. As Ropeik and Gray (2002) have recently suggested, often popular understandings of risk in the general public do not match the scientific facts. Risk communication often seeks to identify persuasive strategies so that the public can be convinced of a particular view regarding some risk. Among the common strategies are the use of technical experts or others who have high credibility as well as the skill in translating scientific information to messages appropriate for lay audiences. Thus, failure to accept this technical view of risk is framed as ineffective communication, poor trust, low credibility, or a case of misunderstanding. In addition, much of risk communication is grounded in the use of fear appeals in persuasive messages (Witte et al., 2000). These risk communication messages introduce a threat, such as the possibility of a health harm given a set of conditions. A change in the conditions, such as the modification of some lifestyle behavior, is then proposed as a way to alleviate the threat. This problem-solution message structure is well established as a basic form of persuasion (Witte et al., 2000).

Risk and crisis communication have much in common and intersect at a variety of points. In fact, some suggest that crisis communication is a more limited form of risk communication (Lundgren, 1994). Both forms of communication involve the production of public messages designed to create specific responses by the public. In both cases, the messages largely are mediated through mass communication channels, although they also have public communication and group communication dimensions. Risk communication and crisis communication each rely on credibility as a fundamental persuasive attribute, although they manifest in different ways. 
Both share an essential purpose of seeking to limit, contain, mitigate, and reduce public harm. Beyond these fundamental commonalties, risk and crisis communication diverge in important ways. These differences are outlined in Table 1.

The basic goals of risk and crisis communication, for example, differ. Risk messages concern the probabilities of some harm and associated methods for reducing the probability of the harm. Risk messages often are grounded in both current scientific and technical understanding of a specific risk factor as well as cultural or social beliefs regarding the risk. The risk messages seek to translate or operationalize technical understanding of risk into behaviors through persuasion. This often requires addressing the cultural or social factors. Messages about crisis, in contrast, typically concern both what is known and what is not known about a specific event. Often such messages are phrased specifically as, "What we know at the present time," and are tempered with discussions about what is being done to collect additional information or mitigate against additional harm. Crisis messages often are focused more directly on informing than persuading. Risk communication has expanded as understandings of risk, particularly technical and scientific, have expanded and with increased public pressure for more information. This form of communication has become increasingly ubiquitous and almost routine as a form of public message. Crisis communication, in contrast, has remained largely event specific, although precrisis planning has encouraged emergency managers to move beyond the confines of a specific event. Crisis communication is essentially nonroutine and much more time

Table 1. Distinguishing features of risk and crisis communication

\begin{tabular}{ll}
\hline Risk communication & Crisis communication \\
\hline $\begin{array}{c}\text { Messages regarding known } \\
\text { probabilities of negative }\end{array}$ & $\begin{array}{c}\text { Messages regarding current state or } \\
\text { conditions regarding a specific }\end{array}$ \\
consequences and how they & event; magnitude, immediacy \\
may be reduced; addressing & duration and control/remediation; \\
technical understandings & cause, blame, consequences \\
(hazards) and cultural beliefs & \\
(outrage) & \\
Principally persuasive, i.e., & Principally informative, i.e., news \\
advertising and public & disseminated through media or \\
education campaigns & broadcast through warning system \\
Frequent/routine & Infrequent/nonroutine \\
Sender/message centered & Receiver/situation centered \\
Based on what is currently & Based on what is known and \\
known, i.e., scientific projections & what is not known \\
Long-term (precrisis) Message & Short-term (crisis) Less preparation, \\
preparation, i.e., campaign & i.e., responsive \\
Technical expert, scientist & Authority figures/emergency manager, \\
Personal scope & technical experts \\
Mediated; commercials, ads & Personal, community, or regional scope \\
brochures, pamphlets & Mediated; press conferences, press releases, \\
Controlled and structured & speeches, websites \\
\hline & Spontaneous and reactive \\
\hline
\end{tabular}


and event bound to the specific conditions of a particular crisis. Risk communication is largely sender/message centered in the sense that time is available to carefully craft a message, identify and test appeals, and disseminate the message through targeted media channels. Crisis communication is more sender/event oriented in that it seeks to respond to immediate public needs for information in what is often a much more spontaneous, and less controlled, manner. Because they are more spontaneous, crisis messages typically are less polished and more often take the form of news conferences or announcements covered in print and broadcast news outlets. Crisis messages also take advantage of whatever channel of communication is available at the time of the event. Radio, for example, given its flexibility and very wide availability, is a particularly important medium for crisis communication. A significant proportion of the public learned about the 9/11 attacks, for example, by radio (Seeger, Vennette, Ulmer, \& Sellnow, 2002).

\section{Crisis and Emergency Risk Communication}

Recently, efforts have been made to combine notions of risk communication and crisis communication into a practice described as crisis and emergency risk communication (Reynolds, 2002). These efforts have been lead by the Centers for Disease Control and Prevention and are in response to a recognition that health communication in an era of bioterrorism as well as other emerging global threats to public health must be strategic, broad based, responsive, and highly contingent. This blended form of communication emphasizes the developmental features of crisis and the various communication needs and exigencies of audiences at various points in the ongoing development of an event. As such, it embraces a process view of crisis as beginning with preevent stages of risk and risk development, moving through the eruption of some triggering event during crisis stages and into postmortem and clean up phases (see Coombs, 1995; Seeger et al., 1998). ${ }^{1}$ The scope and nature of these communication efforts is broader than many traditional models of risk or crisis communication. For example, during the precrisis stage, traditional notions of health promotion and risk communication are appropriate to both educate the public regarding potential threats and to encourage appropriate preparation and riskreducing behaviors. Recent efforts to educate the public more broadly about small pox, communicate the risk of vaccinations, and generally promote vaccination to specific publics could be understood as a kind of health promotion and education. This public education campaign, however, was framed within the larger backdrop of a potential bioterrorism threat that, if manifest, would result in a widespread public health and national security crisis. In addition, specific advice from the federal Department of Homeland Security regarding family disaster plans and kits, for example, is a broad-based campaign designed to persuade the general public to undertake specific activities in preparation for possible attacks (Department of Homeland Security, 2003).

${ }^{1} \mathrm{~A}$ variety of developmental stages of crisis have been described in communication research and disaster studies. In general, these developmental approaches are called models of crisis development although they also might be describe as frameworks. Although Reynolds's (2002) CERC model uses five stages, others have six-stage (Turner, 1976) and three-stage models of crisis development (Coombs, 1995; Ray, 1999; Seeger et al., 1998). Regardless of the specific stages or phases described, there is a general recognition that crises have developmental features. 
It is important to point out that at some level these kinds of precrisis promotions and warnings have occurred in other, albeit much more limited, contexts with regard to more familiar and routine risks. Regions of the country that regularly experience severe weather, such as hurricanes or blizzards, routinely have employed preevent promotions through local or state emergency management offices to increase preparation. These typically include encouraging residents to stockpile disaster supplies such as flashlights, batteries, water, food, and critical medications, and to monitor weather conditions. In addition, residents frequently are advised to evacuate in the cases of an extreme hurricane threat (see Quarantelli, 1980). Prior to influenza season, public health campaigns frequently are mounted by state departments of public health to encourage vaccinations. The American Red Cross, with its emphasis on disaster relief, also has been a traditional proponent of this emergency preparation (American Red Cross, 2002).

When a threat does erupt into the crisis stages, different communication exigencies and audiences emerge. This includes an immediate threat and compressed timeframe requiring a more direct response. There is, for example, an immediate audience of those affected by the crisis. This includes victims, potential victims, close family members, emergency workers, first responders, and others directly affected by the event. Timely communication with this group may help mitigate or contain harm. A much larger audience, usually represented through the media, involves the general public. The immediate communication needs are to reduce the uncertainty, allowing audiences to create a basic understanding of what happened so that they may act appropriately. Without such basic information, both the general public and affected groups may not be able to make sense of the event and may engage in activities that actually increase the relative level of harm. It is not uncommon, for example, for volunteers to rush to the scene of a disaster and actually impede the emergency response. Beyond this, the crisis stage may require that public health communicators issue specific recommendations about how to avoid or reduce harm, what symptoms might indicate concern, and where to go for treatment. Messages recommending evacuation or sheltering in place, for example, often accompany large-scale crisis events. Public health officials struggled during the anthrax episode to provide sufficiently precise information about the symptoms of inhalation anthrax to allow the lay public to assess whether they needed to seek medical attention. This problem was compounded by the similarity of symptoms to other common respiratory illnesses. In addition, crisis communication also seeks to reduce generalized anxiety and concern among the larger public. Those who are not directly affected but have high levels of anxiety are sometimes described as the "worried well." Without adequate information regarding the nature of the event and the risk they face, these "worried well" may overwhelm existing medical capacity. Many emergency crisis plans, therefore, include provisions for secondary assessment centers for those who were not directly or immediately affected. Communicating timely information to the public regarding these kinds of centers is a core function of crisis communication.

The final elements of an emergency or crisis generally are described as postcrisis stages (Coombs, 1995; Seeger, Sellnow, \& Ulmer, 1998). Postcrisis is most often characterized as a period of postmortem, assessment, learning, and constitution of new understandings of risk and risk avoidance (see Seeger, Sellnow, \& Ulmer, in press; Turner, 1976). In many instances, postcrisis is also a period when the media and the public become more critical and questioning regarding the cause of the crisis, the appropriateness of responses and who should take the, blame and 
responsibility. In several states, for example, the outbreak of West Nile Virus has been followed by accusations that public health officials and municipal and state governments had not taken sufficient action or did not respond quickly enough. These critiques and criticism have resulted in new policies and procedures regarding monitoring, spraying for mosquitoes, and disseminating larvacide. The recent episode of anthrax-contaminated mail resulted in similar public critiques and second guessing of official response. The postcrisis stages, while no longer including a sense of immediate threat, require ongoing communication regarding new understandings of risk and amended procedures and policies for risk avoidance.

\section{A Working Model of CERC}

The blended form of crisis and risk communication, then, incorporates principles of effective risk communication and crisis communication throughout the evolution of a risk factor into a crisis event and on through the clean-up and recovery phase. A preliminary model of this process is presented in Table 2.

The five-stage CERC model assumes that crises will develop in largely predictable and systematic ways: from risk, to eruption, to clean-up and recovery on into evaluation. One important value to this systematic approach is that it reduces uncertainty and allows crisis managers to look ahead and anticipate subsequent communication needs and problems. Some potential crises and emergencies may not follow this sequence due to a variety or factors including effective risk during the early stages, the emergence of secondary shocks, or unanticipated interactions. Some observers have, for example, described a kind of chronic crisis that develops into crisis stages for longer periods of time. Some infectious diseases and epidemics may more typically follow this pattern. In addition, it is important to recognize that all crises can be expected to have unforeseen, nonlinear dimensions and interactions that preclude managers from making precise predications (Seeger, 2002b). Unanticipated audiences and audience needs may emerge. New unforeseen threats may compound the risk and require a new set of communication exigencies and strategies. In some disasters, channels of public communication are compromised, requiring that risks and warnings be disseminated in alternative ways. Important crisis management personnel may be injured or unavailable. Crises are inherently equivocal situations, and crisis managers should avoid approaching these events or communicating about them in unequivocal ways. ${ }^{2}$ Regardless of these limitations, the CERC model offers a comprehensive approach within which risk and warning messages and crisis communication activities can be connected into a more encompassing communication form.

\section{Conclusion}

Changes in the nature and scope of crises and emergencies, in the levels and kinds of threats faced by the public and in the ubiquitous nature of media coverage, require

${ }^{2}$ This issue frames part of an ongoing debate in crisis and risk communication (Seeger, 2002a). Risk communication typically would suggest that public messages be unequivocal regarding the risks and associated actions. Crisis communication typically would suggest acknowledging the general uncertainty in a crisis as part of the public statements made about the crisis. Sandman (2003) acknowledged the need to be equivocal in his critique of the CDC's communication efforts regarding SARS. 
Table 2. A working model of CERC

I. Precrisis (Risk Messages; Warnings; Preparations)

Communication and education campaigns targeted to both the public and the response community to facilitate:

- Monitoring and recognition of emerging risks

- General public understanding of risk

- Public preparation for the possibility of an adverse event

- Changes in behavior to reduce the likelihood of harm (self-efficacy)

- Specific warning messages regarding some eminent threat

- Alliances and cooperation with agencies, organizations, and groups

- Development of consensual recommendations by experts and first responders

- Message development and testing for subsequent stages

II. Initial Event (Uncertainty Reduction; Self-efficacy; Reassurance)

Rapid communication to the general public and to affected groups seeking to establish:

- Empathy, reassurance, and reduction in emotional turmoil

- Designated crisis/agency spokespersons and formal channels and methods of communication

- General and broad-based understanding of the crisis circumstances, consequences, and anticipated outcomes based on available information

- Reduction of crisis-related uncertainty

- Specific understanding of emergency management and medical community responses

- Understanding of self-efficacy and personal response activities (how/where to get more information)

III. Maintenance (Ongoing Uncertainty Reduction; Self-efficacy; Reassurance)

Communication to the general public and to affected groups seeking to facilitate:

- More accurate public understandings of ongoing risks

- Understanding of background factors and issues

- Broad-based support and cooperation with response and recovery efforts

- Feedback from affected publics and correction of any misunderstandings/rumors

- Ongoing explanation and reiteration of self-efficacy and personal response activities (how/where to get more information) begun in Stage II.

- Informed decision making by the public based on understanding of risks/benefits

IV. Resolution (Updates Regarding Resolution; Discussions about Cause and New Risks/New Understandings of Risk)

Public communication and campaigns directed toward the general public and affected groups seeking to:

- Inform and persuade about ongoing clean-up, remediation, recovery, and rebuilding efforts 
Table 2. (Continued)

- Facilitate broad-based, honest, and open discussion and resolution of issues regarding cause, blame, responsibility, and adequacy of response.

- Improve/create public understanding of new risks and new understandings of risk as well as new risk avoidance behaviors and response procedures

- Promote the activities and capabilities of agencies and organizations to reinforce positive corporate identity and image

\section{Evaluation (Discussions of Adequacy of Response; Consensus About Lessons and New Understandings of Risks)}

Communication directed toward agencies and the response community to:

- Evaluate and assess responses, including communication effectiveness

- Document, formalize, and communicate lessons learned

- Determine specific actions to improve crisis communication and crisis response capability

- Create linkages to precrisis activities (Stage I)

more comprehensive approaches to communication. The CERC model merges many existing activities into more comprehensive systems of communication and grounded in a recognition of the broad developmental features of crisis. This approach also acknowledges that effective communication regarding crises and emergencies must begin long before an event erupts and continue after the immediate threat has subsided. In many ways, then, CERC is an acknowledgment that risks are ubiquitous and that emergencies and crises that threaten the public health and well-being are likely to be increasingly common.

\section{References}

American Red Cross. (2002). American Red Cross. Retrieved, October 12, 2002, from http://www.Redcross.org

Auf Der Heide, E. (1989). Disaster response: Principles of preparation and coordination. Portland, OR: Book News.

Barton, L. (2001).Crisis in organizations II. Cincinnati, OH: South-Western College Publishing. Centers for Disease Control and Prevention (CDC). (2003). Centers for Disease Control and Prevention. Retrieved April 20, 2003, from http://www.cdc.gov

Coombs, W. T. (1995). The development of guidelines for the selection of the "appropriate" crisis response strategies. Management Communication Quarterly, 4, 447-476.

Coombs, W. T. (1999). Ongoing Crisis Communication: Planning, Managing, and Responding. Thousand Oaks, CA: Sage.

Covello, V. T. (1992). Risk communication: An emerging area of health communication research. In S. A. Deetz (Ed.), Communication yearbook 15 (pp. 359-373). Newbury Park, CA: Sage.

Department of Homeland Security. (2003). Ready. Gov. Retrieved April 13, 2003, from http://www.ready.gov

Egbert, N. \& Parrott, R. (2001). Self-efficacy and rural women's performance of breast and cervical cancer detection practices. Journal of Health Communication, 6, 219-233. 
Fearn-Banks, K. (2002). Crisis communications 2nd ed., Mahwah, NT: Lawrence Erlbaum Associates, Inc.

Fischhoff, B. \& Downs, J. S. (2001). Communicating foodborne disease risk. Emerging infectious diseases, 3, 4. [On-line]. Available: http://www.cdc.gov/ncidod/eid/vol3no4/ fischof.htm

Freimuth. V., Linnan, H. W., \& Potter, P. (2000). Communicating the threat of emerging infections to the public. Emerging Infectious Diseases, 6, 4. [On-line]. Available: http://www.cdc.gov/ncidod/eid/vol6no4/freimuth.htm

Guth, D. W. (1995). Organizational crisis experience and public relations roles. Public Relations Review, 21(2), 123-136.

Heath, R. L. (1994). Environmental risk communication: Cases and practices along the Texas Gulf coast. In B. R. Burelson (Ed.), Communication yearbook 18 (pp. 225-277). Newbury Park, CA: Sage.

Lundgren, R. E. (1994). Risk communication: A handbook for communicating environmental, safety and health risks. Columbus, $\mathrm{OH}$ : Battelle Press.

Mileti, D. S. \& Sorensen, J. H. (1990). Communication of emergency public warnings. Washington, DC: Federal Emergency Management Administration.

Murray-Johnson, L., Witte, K., Liu, W., \& Hubbel, A. P. (2001). Addressing cultural orientations in fear appeals: Promoting AIDS-protective behaviors among Mexican immigrant and African American adolescents and American and Taiwanese college students. Journal of Health Communication, 6, 335-358.

National Council on Radiation Protection \& Measurement. (2001). Management of terrorist events involving radiological materials. Bethesda, MD: National Council on Radiation Protection \& Measurement.

National Research Council. (1989). Improving risk communication. Washington, DC: National Academy Press.

Pauchant, T. C. \& Mitroff, I. I. (1992). Transforming the crisis-prone organization. San Francisco: Jossey-Bass Publishers.

Powell, D. A. \& Leiss, W. (1997). Mad cows and mother's milk: The perils of poor risk communication. Buffalo, NY: McGill-Queen's University Press.

Quarantelli, E. L. (1980). Evacuation behavior and problems: Findings and implications from the research literature. Monograph \#16. Newark, DE: Disaster Research Center, University of Delaware.

Ray, S. J. (1999). Strategic communication in crisis management: Lessons from the airline industry. Westport, CT: Quorum.

Reynolds, B. (2002). Crisis and emergency risk communication. Atlanta, GA: Centers for Disease Control and Prevention.

Rogers, R. W. \& Deckner, C. W. (1975). Effects of fear appeals and physiological arousal upon emotion, attitudes and cigarette smoking. Journal of Personality and Social Psychology, 32, 222-230.

Ropeik, D. \& Gray, G. (2002). Risk: A practical guide for deciding what's really safe and what's really dangerous in the world around you. Boston, MA: Houghton-Mifflin.

Sandman, P. M. (1993). Responding to community outrage: Strategies for effective risk communication. Fairfax, VA: American Industrial Hygiene Association.

Sandman, P. (2002). Smallpox vaccination: Some risk communication linchpins. Retrieved May 4, 2003, from http://www.psandman.com/col/SARS-1.htm

Sandman, P. (2003). "Fear is spreading faster than SARS" - And so it should. Retrieved May 4, 2003, from http://www.psandman.com/col/SARS-1.htm

Seeger, M. (2002a, November). Distinguishing risk communication and crisis communication: Some preliminary thoughts about the anthrax episode. Paper presented at the National Communication Association Conference, New Orleans, LA.

Seeger, M. W. (2002b). Chaos and crisis: Propositions for a general theory of crisis communication. Pubic Relations Review, 28, 329-337. 
Seeger, M. W. \& Bolz, B. (1996). Technological transfer and multinational corporations in the Union Carbide crisis Bhopal, India. In J. A. Jaksa \& M. S. Pritchard (Eds.), Responsible communication: Ethical issues in business, industry, and the professions (pp. 245-265). Cresskill, NJ: Hampton Press.

Seeger, M. W., Sellnow, T. L., \& Ulmer, R. R. (1998). Communication, organization and crisis. In M. E. Roloff (Ed.), Communication Yearbook 21. Thousand Oaks, CA: Sage.

Seeger, M. W., Sellnow, T. L., \& Ulmer, R. R. (2001). Public relations and crisis communication: Organizing and chaos. In R. L. Heath (Ed.), Public relations handbook (pp. 155-166). Thousand Oaks, CA: Sage.

Seeger, M. W., Sellnow, T. L., \& Ulmer, R. R. (2003). Communication, organization and crisis. West port, CT: Quorum.

Seeger, M. W., Vennette, S., Ulmer, R. R., \& Sellnow, T. L. (2002). Media use, information seeking, and reported needs in post crisis contexts. In B. S. Greenberg (Ed.), Communication and terrorism: Public and media responses to 9/11 (pp. 53-63). Cresskill, NJ: Hampton Press.

Sellnow, T., Seeger, M., \& Ulmer, R. R. (2002). Chaos theory, informational needs and the North Dakota floods. Journal of Applied Communication Research, 30(3), 269-292.

Small, W. (1991). Exxon Valdez: How to spend billions and still get a black eye. Public Relations Review, 17(1), 9-26.

Smart, R. G. \& Fejer, D. (1974). The effects of high and low fear messages about drugs. Journal of Drug Education, 16, 32-37.

Sorensen, J. H. (2000). Hazard warning systems: Review of 20 years of progress. Natural Hazards Review, 1(2), 119-125.

Turner, B. (1976). The organizational and interorganizational development of disasters. Administrative Science Quarterly, 21, 378-397.

Ulmer, R. R. \& Sellnow, T. L. (2000). Consistent questions of ambiguity in organizational crisis communication: Jack in the box as a case study. Journal of Business Ethics, 25(2), $143-155$.

Wilcox, D. L., Ault, P. H., \& Agee, W. K. (1986). Public relations strategies and tactics. New York: Harper \& Row.

Witte, K. (1992). Preventing AIDS through persuasive communications: A framework for constructing effective, culturally specific, preventative health messages. International and Intercultural Health Communication Annual, 16, 67-86.

Witte, K. (1995). Generating effective risk messages: How scary should your risk communication be? In B. R. Burleson (Ed.), Communication yearbook (vol. 18, pp. 229-254). Thousand Oaks, CA: Sage.

Witte, K., Meyer, G., \& Martel, D. (2000). Effective health risk messages. Thousand Oaks, CA: Sage. 